Western University Scholarship@Western

FIMS Publications

Information \& Media Studies (FIMS) Faculty

2005

\title{
Interpretive Repertoires
}

Pamela J. McKenzie

University of Western Ontario, pmckenzi@uwo.ca

Follow this and additional works at: https://ir.lib.uwo.ca/fimspub

Part of the Library and Information Science Commons

Citation of this paper:

McKenzie, Pamela J., "Interpretive Repertoires" (2005). FIMS Publications. 45.

https://ir.lib.uwo.ca/fimspub/45 


\title{
Interpretative Repertoires
}

\author{
Pamela J. McKenzie \\ Faculty of Information and Media Studies \\ University of Western Ontario \\ pmckenzi@uwo.ca
}

The interpretative repertoire is a theoretical and analytical concept used in some forms of discourse analysis. The term was developed by social psychologists, including Jonathan Potter and Margaret Wetherell, in response to the understanding among social psychologists that action results from processes operating within the heads of individuals. Such an understanding assumes that language and people are separate entities, and that language is a neutral medium between the social actor and the world. Accounts are therefore taken as transparent representations of events or mental states. Analysis within this paradigm relates to the truth or faithfulness of an account, or uses accounts as evidence of underlying processes. This analysis tends to look for similarities rather than variations within and across accounts, to aggregate accounts into categories such as “attitudes,” and to downplay or discount the social situatedness of action.

A constructionist perspective, on the other hand, places an emphasis “on discourse as the vehicle through which the self and the world are articulated, and on the way different discourses enable different versions of selves and reality to be built” (Tuominen, Talja, \& Savolainen, 2002 p. 273). Of critical importance is the assumption that "the things we hold as facts are materially, rhetorically, and discursively crafted in institutionalized social practices” (p. 278).

Potter and Wetherell's form of discourse analysis (described in detail in Potter \& Wetherell, 1987; Potter, 1996; and Wetherell, Taylor and Yates, 2001) is developed from the 
study of language use in a variety of disciplines. It builds on ethnomethodology, speech act theory, and semiology to explain how people use language to construct versions of the social world. Their perspective on discourse analysis recognizes that language allows for multiple versions of an event. This analysis is therefore concerned with the ways that individuals construct their versions to do things. In particular, a study of the variations in language use can shed light on the ways that speakers and writers construct their accounts and structure them to appear factual (the epistemological orientation of discourse), and the ways that they use accounts to serve rhetorical functions (the action orientation of discourse).

A constructionist perspective does not assume that an individual will represent people and events consistently over time. Rather, an individual is expected to develop a variety of different representations, depending on the function performed by the account. For example, one might tell two quite different stories when describing a night of youthful excess to a parent or to a room-mate. Regularity within the accounts of a single individual is therefore less interesting than the regularity that exists in the elements used by different speakers to describe the same person, event, or thing. Potter and Wetherell argue that a range of accounts of the same phenomenon will contain the same "relatively internally consistent, bounded language units which we have called ... interpretative repertoires” (Wetherell \& Potter, 1988 p.171). The interpretative repertoire is a key component of this form of discourse analysis_-as Wetherell and Potter (1988, p. 172) explain:

Repertoires could be seen as building blocks speakers use for constructing versions of actions, cognitive processes, and other phenomena. Any particular repertoire is constructed out of a restricted range of terms used in a specific stylistic and grammatical fashion. Commonly these terms are derived from one or more key metaphors and the 
presence of a repertoire will often be signaled by certain tropes or figures of speech. Identifying and analyzing interpretative repertoires is a major methodological component of discourse analysis. Data collection and analysis therefore revolve around several core requirements:

- Considering the account itself to be the primary object of research rather than seeing it as a transparent representation of an individual's attitudes and beliefs or the true nature of events;

- Working with examples of language as it is actually used (transcripts or written texts) rather than summaries or paraphrases, and paying close attention to patterns in language use within examples;

- Focusing on variations in the ways discourse is constructed, both within and across accounts, in order to begin to understand the epistemological and action orientations of specific versions.

The work of Potter and Wetherell was developed for and has been used extensively in social psychology. It is therefore related to other constructionist approaches—such as social positioning theory—in that discipline, as interpretative repertoires may be used to construct positions for one's self or others. This approach has also been used widely beyond social psychology. A search of Web of Science (February 9, 2004) identified a total of nearly 1200 citations to the two central works explaining the use of interpretative repertoires (898 citations to Potter \& Wetherell, 1987 and 278 to Potter, 1996). Recent studies citing these works and using the interpretative repertoire come from disciplines as diverse as management, forestry, addiction studies, women's health, and human-computer interaction. In information studies, Potter and Wetherell's work has been used to study the ways that accounts are constructed—for example, 
the ways that "technology" is reproduced as a series of interests (Jacobs, 2001) and the ways that authority claims are made, contested, and defended (McKenzie, 2003)—and the ways that information seeking and use can take discursive action (Tuominen and Savolainen, 1996).

As an analytic unit, the interpretative repertoire shows promise for those responding to Tuominen, Talja, and Savolainen’s (2002; Tuominen \& Savolainen, 1996) calls for a constructionist metatheory in library and information science. Analyzing the interpretative repertoires used by information seekers can assist us in understanding the ways that information seeking and information sources are constructed in local discursive encounters. A study of the epistemological orientation of discourse may provide insights into the techniques speakers and writers use to evaluate information sources or information-seeking strategies. An analysis of the action orientation of discourse could show how information seekers within specific contexts justify their information behavior. Like other constructionist approaches, the use of interpretative repertoires has the potential to "[shift] the focus of research from understanding the needs, situations, and contexts of individual users to the production of knowledge in discourses, that is, within distinct conversational traditions and communities of practice” (Tuominen, Talja, \& Savolainen 2002, p.273).

Jacobs, N. (2001). Information technology and interests in scholarly communication: A discourse analysis. Journal of the American Society for Information Science and Technology, 52(13), 1122-33.

McKenzie, P. J. (2003). Justifying cognitive authority decisions: discursive strategies of information seekers. Library Quarterly, 73(3), 261-288. 
Potter, J. (1996). Representing reality: Discourse, rhetoric and social construction. Thousand Oaks CA: Sage.

Potter, J., \& Wetherell, M. (1987). Discourse and social psychology; beyond attitudes and behaviour. London: Sage.

Tuominen, K., \& Savolainen, R. (1996). A social constructionist approach to the study of information use as a discursive action. P. Vakkari, R. Savolainen, \& B. Dervin (eds), Information seeking in context: proceedings of an international conference in information needs, seeking and use in different contexts, 14-16 August, 1996, Tampere, Finland (pp. 81-96). London: Taylor Graham.

Tuominen, K., Talja, S., \& Savolainen, R. (2002). Discourse, cognition, and reality: Toward a social constructionist metatheory for library and information science. In H. Bruce, R. Fidel, P. Ingwersen, \& P. Vakkari, (Eds.), Emerging frameworks and methods: CoLIS 4. Proceedings of the fourth international conference on conceptions of library and information science, Seattle, WA, USA, July 21-25, 2002. (pp. 271-283). Greenwood Village, CO: Libraries Unlimited.

Wetherell, M., \& Potter, J. (1988). Discourse analysis and the identification of interpretive repertoires. In C. Antaki (Ed.), Analysing everyday explanation: A casebook of methods (pp. 168-183). Newbury Park, CA: Sage. 
Wetherell, M., Taylor, S. \& Yates, S.J. (Eds.). (2001). Discourse theory and practice: A reader . London: Sage. 